\title{
Clinical Outcomes and Clinico-pathological Correlations in Lupus Nephritis with Kidney Biopsy Showing Thrombotic Microangiopathy
}

\author{
Chao Li, Desmond Y.H. Yap, Gavin Chan, Yu-bing Wen, Hang Li, Colin Tang, Xue-mei Li, \\ Xue-wang Li, and Tak Mao Chan
}

ABSTRACT. Objective. Renal thrombotic microangiopathy (TMA) is an uncommon pathological finding in lupus nephritis (LN), and its clinical significance remains to be defined.

Methods. Twenty-four patients with lupus nephritis (LN) and renal TMA were selected from a retrospective review of 677 biopsy-proven LN patients, and compared with 48 LN controls without TMA (1:2 ratio) matched according to demographics and treatments.

Results. Renal TMA was noted in 3.5\% of kidney biopsies of LN. TMA was associated with a higher prevalence of anti-Ro (45.8\% vs 18.8\%; $\mathrm{p}=0.016)$, higher Systemic Lupus Erythematosus Disease Activity Index scores $(21.4 \pm 8.5$ vs $10.8 \pm 2.3 ; \mathrm{p}<0.001)$, lower estimated glomerular filtration rate (eGFR; $16.8 \pm 11.7 \mathrm{ml} / \mathrm{min}$ vs $77.8 \pm 28.6 \mathrm{ml} / \mathrm{min} ; \mathrm{p}<0.001)$, and a higher percentage of patients who required dialysis $(37.5 \%$ vs $2.1 \%$; p < 0.001$)$ at the time of kidney biopsy. Activity and chronicity indices [median (range)] were higher in the TMA group [11 (2-19) and 3 (1-8), respectively, compared with $7(0-15)$ and $1(0-3)$ in controls; $p=0.004$ and $p<0.001$; respectively]. Patients with TMA showed inferior 5-year renal survival and higher incidence of chronic kidney disease at last followup (70\% and $66.6 \%$, respectively, compared with $95 \%$ and $29.2 \%$ in controls; $p=0.023$ and 0.002 , respectively). The TMA group also showed lower median eGFR compared with controls [50.1 (IQR 7-132) $\mathrm{ml} / \mathrm{min}$ vs 85.0 (IQR 12-147) $\mathrm{ml} / \mathrm{min} ; \mathrm{p}=0.003$ ]. Five-year patient survival rate was similar between the 2 groups ( $87 \%$ and $98 \%$ in TMA and control group, respectively; $\mathrm{p}=0.127$ ).

Conclusion. TMA in kidney biopsy was associated with more severe clinical and histological activity, and significantly inferior longterm renal outcome in LN. (First Release July 1 2019; J Rheumatol 2019;46:1478-84; doi:10.3899/jrheum.180773)

Key Indexing Terms:

LUPUS NEPHRITIS

THROMBOTIC MICROANGIOPATHY

OUTCOMES

From the Division of Nephrology, Peking Union Medical College Hospital, Chinese Academy of Medical Sciences and Peking Union Medical College, Beijing, China; Division of Nephrology, Department of Medicine, Queen Mary Hospital, University of Hong Kong; Department of Pathology, Queen Mary Hospital, Hong Kong.

C. Li, MD, Division of Nephrology, Peking Union Medical College Hospital, Chinese Academy of Medical Sciences and Peking Union Medical College; D.Y. Yap, MBBS, MD, Division of Nephrology, Department of Medicine, Queen Mary Hospital, University of Hong Kong; G. Chan, MBBS, Department of Pathology, Queen Mary Hospital; Y.B. Wen, MMed, Division of Nephrology, Peking Union Medical College Hospital, Chinese Academy of Medical Sciences and Peking Union Medical College; H. Li, MD, Division of Nephrology, Peking Union Medical College Hospital, Chinese Academy of Medical Sciences and Peking Union Medical College; C. Tang, BSc, MSc, Division of Nephrology, Department of Medicine, Queen Mary Hospital, University of Hong Kong; X.M. Li, MD, PhD, Division of Nephrology, Peking Union Medical College Hospital, Chinese Academy of Medical Sciences and Peking Union Medical College; X.W. Li, MMed, Division of Nephrology, Peking Union Medical College Hospital, Chinese Academy of Medical Sciences and Peking Union Medical College; T.M. Chan, MBBS, MD, Division of Nephrology, Department of Medicine, Queen Mary Hospital, University of Hong Kong. CL and DYY contributed equally to this work. Address correspondence to Prof. T.M. Chan, Department of Medicine, Queen Mary Hospital, 102 Pokfulam Road, The University of Hong Kong, Hong Kong.E-mail:dtmchan@hku.hk; or Prof.X.M.Li, Department of Nephrology, Peking Union Medical College Hospital, No. 1, Shuaifuyuan, Dongcheng District, Beijing, 100730,China.E-mail: lixmpumch@126.com Accepted for publication February 13, 2019.
Lupus nephritis (LN) is a severe organ involvement in systemic lupus erythematosus (SLE), and an important cause of chronic kidney disease (CKD) and mortality ${ }^{1,2}$. Histological confirmation of LN is based on the International Society of Nephrology and Renal Pathology Society (ISN/RPS) 2003 Classification, which largely focuses on glomerular lesions and recommends that renal vascular lesions be reported as separate entries ${ }^{3}$. Renal vascular lesions are recognized in LN and previous studies have suggested that inclusion of these pathological features in LN classification might have additional prognostic value ${ }^{4}$. Thrombotic microangiopathy (TMA) is an important renal vascular lesion characterized by endothelial cell swelling, lumen narrowing, or thrombi formation in the interlobular arteries, arterioles, and glomerular capillaries ${ }^{5}$. Renal TMA in LN may or may not be associated with thrombogenic autoantibodies such as lupus anticoagulant (LAC) or antiphospholipid antibodies (aPL) ${ }^{5}$. Renal TMA has been associated with unfavorable renal outcomes in classical hemolytic uremic syndrome (HUS) secondary to infections, atypical HUS due to complement cascade defects, thrombotic thrombocytopenic purpura (TTP), and malignant hyper-

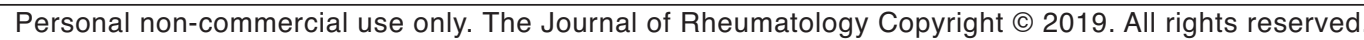


tension $(\mathrm{HTN})^{6,7}$, but reported findings in patients with $\mathrm{LN}$ have been variable and inconclusive, likely attributed to the limited experience owing to small sample size $e^{4,8,9}$. The pathogenesis of $\mathrm{LN}$ is multifactorial involving both genetic and acquired abnormalities in immune-mediated inflammatory processes, and the disease manifestations and response to treatment vary considerably between patients and are subject to the effect of race and environmental factors $^{2,10,11}$. Asian patients with SLE have a higher prevalence of LN, but data from some Asian populations show that treatment response and prognosis are favorable in most patients, provided that diagnosis is not delayed and treatment is administered before extensive irreversible renal damage ${ }^{1,12-18}$. One previous study from Taiwan reported the clinical characteristics and short-term patient survival data of systemic TMA in 25 SLE patients, with complete renal remission rate of $44 \%{ }^{19}$. Another report from mainland China showed poor renal outcomes in LN patients with renal TMA, but the study population included patients with TTP, antiphospholipid syndrome, malignant HTN, and systemic sclerosis $(\mathrm{SSc})^{9}$. While it is generally perceived that renal TMA is a significant finding, there is relatively little systematic analysis of renal TMA in patients on LN because of the low incidence, especially with regard to clinico-pathological correlations and longterm renal survival.

\section{MATERIALS AND METHODS}

We performed a retrospective study on patients with biopsy-proven $\mathrm{LN}$ from 2 centers, at Queen Mary Hospital, Hong Kong, and Peking Union Medical College Hospital, Beijing, China, respectively, to identify patients with features of TMA in the kidney biopsy that showed LN, and to examine the clinico-pathological associations and the outcomes of $\mathrm{LN}$ patients with renal TMA.

Patients. The case records and kidney biopsy slides of all patients with biopsy-proven $\mathrm{LN}$ who were under the care of the 2 centers during the period of January 2002 to December 2016 were reviewed. The diagnosis of SLE was according to the revised American College of Rheumatology classification ${ }^{20}$, and that of LN was according to the 1982 World Health Organization classification for LN until 2004, then the ISN/RPS 2003 classification afterward ${ }^{3}$. Kidney biopsies prior to 2004 were reviewed and reclassified according to the ISN/RPS 2003 classification. Patients with kidney biopsies showing both LN and renal TMA (as described below) were selected. Considering that patient and renal survival can be affected by patient demographics, duration of followup after kidney biopsy, class of LN, as well as induction and maintenance treatments, we reviewed all LN patients and selected non-TMA LN patient controls in 1:2 ratio according to the matching of these variables. Patients were excluded if they had chronic viral hepatitis infection, other concomitant autoimmune diseases, active malignancy, or pregnancy. Data retrieval and analysis was approved by the institutional review boards of the 2 institutes (approval no. UW11-115).

Assessment of renal histopathology. Renal biopsy specimens were examined with light microscopy, immunofluorescence, and electron microscopy by 2 independent pathologists, and reported according to the ISN/RPS 2003 classification. All histological findings were reevaluated and verified by a third independent renal pathologist at Queen Mary Hospital, Hong Kong. Renal TMA was defined as endothelial cell swelling, lumen narrowing or obliteration, and thrombi formation in interlobular artery, arteriole, and glomerular capillary lesions upon examination by light microscopy (Figure

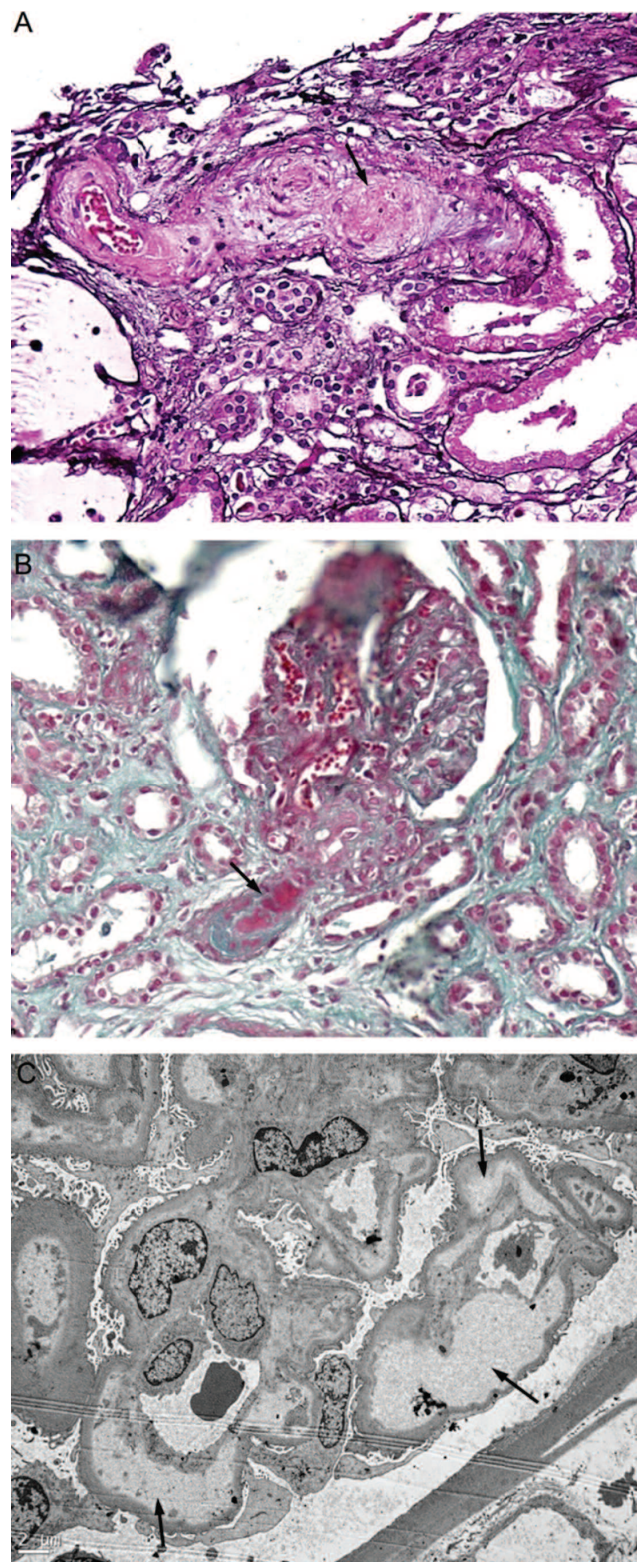

Figure 1. Representative images of renal thrombotic microangiopathy characterized by (A) mucoid intimal thickening in an interlobular arteriole (arrow; silver stain, original magnification $\times 400$ ); (B) thrombosis in an afferent arteriole (arrow; Masson's trichrome, original magnification $\times 400$ ); and (C) subendothelial space expansion (arrows) by subendothelial cells and flocculent material (electron micrograph, original magnification $\times 4000$ ).

1A and 1B) using H\&E, silver, and Masson's trichrome staining. Swelling of glomerular endothelial cells and their detachment from glomerular basement membrane and widening of the subendothelial space were confirmed by electron microscopy (Figure 1C).

Immunosuppressive protocol and adjunctive therapies. Patients with active Class III/IV \pm V LN were treated with prednisolone plus either cyclophosphamide (CYC) or mycophenolate mofetil (MMF; available since 1998) under standard induction and tapering protocols ${ }^{13}$. The period of induction referred to the first 6 months after the commencement of immunosuppressive treatments. Prednisolone was initiated at $0.8-1 \mathrm{mg} / \mathrm{kg} / \mathrm{day}$ and tapered by 5 $\mathrm{mg} /$ day every fortnight to reach $5-7.5 \mathrm{mg} /$ day after about 6 months. CYC was given orally at $1.5-2 \mathrm{mg} / \mathrm{kg} /$ day for 6 months. MMF was commenced

Personal non-commercial use only. The Journal of Rheumatology Copyright $\subset$ 2019. All rights reserved. 
at 1.5-2 g/day and the dose remained unchanged for 6 months if tolerated. Anti-CD20 therapy was not used. Plasmapheresis was used only in patients who showed clinical evidence of systemic TMA (as defined by the presence of thrombocytopenia and evidence of microangiopathic anemia). Maintenance immunosuppression comprised low-dose prednisolone (5-7.5 $\mathrm{mg}$ /day) and either azathioprine (AZA) or MMF. MMF dose was 1-1.5 $\mathrm{g}$ /day during the first 6 months of maintenance immunosuppression, and then gradually reduced according to clinical status. The dose of AZA was 2 $\mathrm{mg} / \mathrm{kg} /$ day during the first 6 months of maintenance immunosuppression, and then gradually reduced according to clinical status. Subsequent rate of dose tapering for the immunosuppressive medications varied between patients depending on clinical stability and prior history of disease relapse. Hydroxychloroquine and renin-angiotensin blocking agents, as well as treatment of hypertension and dyslipidemia, were standard.

Followup schedule and outcome measures. Patients were seen at 2- to 14-week intervals depending on their clinical status. These variables were monitored at every visit: blood pressure, complete blood picture, renal and liver biochemistry, anti-dsDNA (measured by ELISA; BioRad), complement C3 levels (measured by nephelometry; Beckman Coulter), anti-Ro (detected by Ouchterlony double-gel immunodiffusion and Western blotting), aPL (measured by commercially available ELISA assays; QUANTA Lite), LAC (determined by dilute Russell's viper venom test), proteinuria, and clinically significant events. Glucose and lipid profile were measured every 6 months. Complete renal remission (CR) was defined as reduction in urine protein excretion to $<0.5 \mathrm{~g} /$ day together with improved or stable renal function; the latter indicated by a serum creatinine level not higher than $115 \%$ of baseline value. Partial renal remission (PR) was denoted by a decrease in urine protein excretion by $\geq 50 \%$ and in the subnephrotic range, together with improved or stable renal function.

Statistical analysis. Continuous variables were expressed as mean $( \pm \mathrm{SD})$ or median (range), and compared with Student t test or Mann-Whitney U test where appropriate. Categorical variables were expressed as frequency (percentage), and analyzed using chi-square test or Fisher's exact test where appropriate. Patient and renal survival rates were estimated by Kaplan-Meier method. Risk factors for renal failure were analyzed by multivariate Cox regression analysis. All statistical analyses were performed by SPSS 24.0 (IBM Corp.), and p values of 0.05 (2-tailed) were considered statistically significant.

\section{RESULTS}

Patients and clinical characteristics. We reviewed a total of 677 patients with kidney biopsy showing LN and identified 26 cases with renal TMA. Two cases were excluded because the reevaluation of their histology did not show convincing evidence of renal TMA, and we did not identify additional TMA cases upon reevaluation of all kidney biopsies. Therefore, 24 patients (3.5\%) showing renal TMA and 48 matched non-TMA controls were included in the analysis (Table 1). The duration of followup in TMA and non-TMA patients was $48.6 \pm 31.5$ months and $49.2 \pm 23.8$ months, respectively.

Patients with TMA showed a higher seroprevalence rate for anti-Ro antibodies (45.8\%), compared with $18.8 \%$ in non-TMA controls $(\mathrm{p}=0.016)$. There was no difference in the seroprevalence of anti-La, anticardiolipin antibodies, and LAC between the 2 groups ( $p>0.05$ for all). In addition, patients with renal TMA showed higher serum creatinine and lower eGFR levels at presentation $(397.7 \pm 192.4 \mu \mathrm{mol} / \mathrm{l}$ and $16.8 \pm 11.7 \mathrm{ml} / \mathrm{min}$, respectively) compared with non-TMA controls $(94.4 \pm 38.7 \mu \mathrm{mol} / 1$ and $77.8 \pm 28.6 \mathrm{ml} / \mathrm{min}$, respec-
Table 1. Clinical characteristics of lupus nephritis (LN) patients with or without renal thrombotic microangiopathy.

\begin{tabular}{|c|c|c|c|}
\hline Clinical Characteristics & $\begin{array}{l}\text { With Renal } \\
\text { TMA, } \mathrm{n}=24\end{array}$ & $\begin{array}{l}\text { Without Renal } \\
\text { TMA (controls), } \\
n=48\end{array}$ & $\mathrm{p}$ \\
\hline \multicolumn{4}{|l|}{ Patient demographics } \\
\hline Sex, F/M & $22 / 2$ & $44 / 4$ & 1.000 \\
\hline Age, yrs & $27.7 \pm 9.1$ & $28.8 \pm 9.2$ & 0.630 \\
\hline Duration of followup, mos & $48.6 \pm 31.5$ & $49.2 \pm 23.8$ & 0.941 \\
\hline \multicolumn{4}{|l|}{ Class of LN on presentation } \\
\hline Class III or IV & $19(79.2)$ & $38(79.2)$ & 1.000 \\
\hline Class III + V or IV + V & $4(16.6)$ & $8(16.6)$ & 1.000 \\
\hline Class V & $1(4.2)$ & $2(4.2)$ & 1.000 \\
\hline \multicolumn{4}{|l|}{ Induction treatment } \\
\hline $\mathrm{PSL}+\mathrm{CYC}$ & $22(91.7)$ & $42(87.5)$ & 0.640 \\
\hline $\mathrm{PSL}+\mathrm{MMF}$ & $2(8.3)$ & $6(12.5)$ & 0.600 \\
\hline \multicolumn{4}{|l|}{ Maintenance treatment } \\
\hline $\mathrm{PSL}+\mathrm{AZA}$ & $13(54.2)$ & $33(68.8)$ & 0.225 \\
\hline $\mathrm{PSL}+\mathrm{MMF}$ & $6(25.0)$ & $13(27.0)$ & 0.850 \\
\hline $\mathrm{PSL}+\mathrm{MMF}+\mathrm{CNI}$ & $2(8.3)$ & $1(4.2)$ & 0.211 \\
\hline $\mathrm{PSL}+\mathrm{CNI}$ & $3(12.5)$ & $1(4.2)$ & 0.105 \\
\hline \multicolumn{4}{|l|}{ Adjunctive treatments } \\
\hline Antimalarials & $5(20.8)$ & $8(16.7)$ & 0.660 \\
\hline ACEI/ARB & $21(87.5)$ & $34(70.8)$ & 0.120 \\
\hline \multicolumn{4}{|c|}{ Clinical variables on presentation } \\
\hline Anti-Ro seropositivity & $11(45.8)$ & $9(18.8)$ & 0.016 \\
\hline Anti-La seropositivity & $4(16.7)$ & $3(6.3)$ & 0.160 \\
\hline $\begin{array}{l}\text { Anti-cardiolipin IgG/IgM } \\
\text { seropositivity }\end{array}$ & $3(12.5)$ & $8(16.7)$ & 0.643 \\
\hline LAC seropositivity & $3(12.5)$ & $3(6.3)$ & 0.366 \\
\hline Serum creatinine, $\mu \mathrm{mol} / 1$ & $397.7 \pm 192.4$ & $94.4 \pm 38.7$ & $<0.001$ \\
\hline $\mathrm{eGFR}, \mathrm{ml} / \mathrm{min}$ & $16.8 \pm 11.7$ & $77.8 \pm 28.6$ & $<0.001$ \\
\hline $\begin{array}{l}\text { Patients requiring dialysis } \\
\text { on presentation }\end{array}$ & $9(37.5)$ & $1(2.1)$ & $<0.001$ \\
\hline Proteinuria, g/d & $5.3 \pm 3.9$ & $4.2 \pm 2.9$ & 0.292 \\
\hline Anti-dsDNA, IU/ml & $125.4 \pm 164.1$ & $161.3 \pm 125.7$ & 0.387 \\
\hline C3 level, mg/dl & $40 \pm 20$ & $50 \pm 20$ & 0.018 \\
\hline Hemoglobin, g/dl & $7.6 \pm 1.9$ & $10.8 \pm 2.0$ & $<0.001$ \\
\hline Leukocytes, $\times 10^{9} / 1$ & $4.9 \pm 2.4$ & $6.6 \pm 3.9$ & 0.030 \\
\hline Lymphocytes, $\times 10^{9} / 1$ & $0.9 \pm 0.6$ & $1.1 \pm 0.7$ & 0.398 \\
\hline Platelets, $\times 10^{9} / 1$ & $68.3 \pm 63.2$ & $197.6 \pm 87.7$ & $<0.001$ \\
\hline SLEDAI score & $21.4 \pm 8.5$ & $10.8 \pm 2.3$ & $<0.001$ \\
\hline
\end{tabular}

Values are $\mathrm{n}(\%)$ or mean \pm SD unless otherwise specified. TMA: thrombotic microangiopathy; ACEI: angiotensin-converting enzyme inhibitor; ARB angiotensin receptor blocker; AZA: azathioprine; CNI: calcineurin inhibitors; CYC: cyclophosphamide; MMF: mycophenolate mofetil; PSL: prednisolone; LAC: lupus anticoagulant; eGFR: estimated glomerular filtration rate; SLEDAI: Systemic Lupus Erythematosus Disease Activity Index.

tively; $\mathrm{p}<0.001$ for both). More patients with renal TMA required acute hemodialysis at presentation of active nephritis compared to the non-TMA group $(37.5 \%$ and $2.1 \%$, respectively; $\mathrm{p}<0.001)$. Renal TMA patients also had higher SLEDAI scores $(21.4 \pm 8.5$, compared with $10.8 \pm 2.3$ in non-TMA controls). The TMA groups also showed lower $\mathrm{C} 3$ at presentation $(40 \pm 20 \mathrm{mg} / \mathrm{dl}$, compared with $50 \pm 20 \mathrm{mg} / \mathrm{dl}$ in non-TMA patients; $\mathrm{p}=0.018$ ), while the levels of anti-dsDNA antibodies were similar between the 2 groups

Personal non-commercial use only. The Journal of Rheumatology Copyright $\subset$ $\subset$ 2019. All rights reserved 
$(p=0.387)$. LN patients with renal TMA also showed lower hemoglobin, leukocyte, and platelet counts compared with non-TMA controls ( $\mathrm{p}<0.001,0.03$, and $<0.001$, respectively; Table 1).

Renal histopathological features. The median scores of activity index, leukocyte infiltration, fibrinoid necrosis/karyorrhexis, and interstitial infiltrates were higher in the renal TMA group compared with the non-TMA group ( $\mathrm{p}=0.004$, $0.005,0.011$, and $<0.001$, respectively; Table 2 ). The median scores of chronicity index, interstitial fibrosis, and tubular atrophy were also higher in the renal TMA group compared with non-TMA controls ( $p<0.001$ for all; Table 2). We did not identify any case with other features of SLE vasculopathy within the group of 24 patients with renal TMA and the 48 control patients included in this study.

Clinical outcomes. The short-term and longterm clinical outcomes were summarized (Table 3 ). LN patients with TMA achieved comparable $\mathrm{CR}$ rate compared with non-TMA controls $(8.3 \%$ vs $6.3 \%$ and $25.0 \%$ vs $20.8 \%$, at 6 and 12 months, respectively; $p=0.743$ and 0.690 , respectively). The TMA group had lower PR rate at 6 months compared with non-TMA controls $(8.3 \%$ vs $29.2 \%$; $\mathrm{p}=0.045)$, but the difference at 12 months did not reach statistical significance (12.5\% vs $33.3 \%, \mathrm{p}=0.07)$. Mean time-to-CR and time-to-PR in the TMA group was $11.8 \pm 6.6$ months and $8.2 \pm 7.3$ months, respectively, compared with $9.0 \pm 5.0$ months and $6.5 \pm 5.6$ months, respectively, in non-TMA patients $(\mathrm{p}=0.28$ and 0.55 , respectively). Four patients suffered systemic TMA and all were treated with plasmapheresis. Their serum creatinine, eGFR, anti-dsDNA, C3, and SLEDAI score at presentation were $378.8 \pm 226.2 \mu \mathrm{mol} / 1,21.2 \pm 17.4$

Table 2. Renal histological features in lupus nephritis (LN) patients with or without thrombotic microangiopathy on kidney biopsy.

\begin{tabular}{lccc}
\hline Renal Histological Features & $\begin{array}{c}\text { With Renal } \\
\text { TMA, } \mathrm{n}=24\end{array}$ & $\begin{array}{c}\text { Without Renal } \\
\text { TMA (controls), } \\
\mathrm{n}=48\end{array}$ \\
& & $\mathrm{p}$ \\
\hline Class of LN on presentation & & & \\
Class III or IV & $19(79.2)$ & $38(79.2)$ & 1.000 \\
Class III + V or IV + V & $4(16.6)$ & $8(16.6)$ & 1.000 \\
Class V & $1(4.2)$ & $2(4.2)$ & 1.000 \\
Accompanying renal histological features & & \\
Activity index & $11(2-19)$ & $7(0-15)$ & 0.004 \\
Endocapillary proliferation & $3(1-3)$ & $3(1-3)$ & 0.349 \\
Leukocyte infiltration & $1(0-3)$ & $0(0-3)$ & 0.005 \\
Fibrinoid necrosis/karryorrhexis & $1(0-2)$ & $0(0-6)$ & 0.011 \\
Cellular crescents & $1(0-3)$ & $0(0-6)$ & 0.079 \\
Hyaline thrombi/wire loops & $1(0-3)$ & $1(0-3)$ & 0.489 \\
Mononuclear cell infiltrates & $1(0-3)$ & $1(0-1)$ & $<0.001$ \\
Chronicity index & $3(1-8)$ & $1(0-3)$ & $<0.001$ \\
Glomerulosclerosis & $1(0-2)$ & $0(0-3)$ & 0.979 \\
Fibrous crescents & $0(0-1)$ & $0(0-1)$ & 0.050 \\
Interstitial fibrosis & $1(0-3)$ & $0(0-3)$ & $<0.001$ \\
Tubular atrophy & $1(0-3)$ & $0(0-3)$ & $<0.001$ \\
\hline
\end{tabular}

Values are $\mathrm{n}(\%)$ or median (range). TMA: thrombotic microangiopathy.
Table 3. Clinical outcomes of lupus nephritis patients with or without renal thrombotic microangiopathy (TMA).

\begin{tabular}{lccc}
\hline Clinical Outcomes & $\begin{array}{c}\text { With Renal } \\
\text { TMA, n }=24\end{array}$ & $\begin{array}{c}\text { Without Renal } \\
\text { TMA (controls), } \\
\mathrm{n}=48\end{array}$ & $\mathrm{p}$ \\
\hline CR after 6 mos & $2(8.3)$ & $3(6.3)$ & 0.743 \\
CR after 12 mos & $6(25.0)$ & $10(20.8)$ & 0.690 \\
PR after 6 mos & $2(8.3)$ & $14(29.2)$ & 0.045 \\
PR after 12 mos & $3(12.5)$ & $16(33.3)$ & 0.070 \\
5-yr patient survival, \% & 87 & 98 & 0.127 \\
5-yr renal survival, \% & 70 & 95 & 0.023 \\
$\begin{array}{l}\text { Median eGFR at last followup, } \\
\text { ml/min, IQR }\end{array}$ & $50.1(7-132)$ & $85.0(12-147)$ & 0.003 \\
$\begin{array}{l}\text { Patients with stage 3 or above } \\
\text { CKD at last followup }\end{array}$ & $16(66.6)$ & $14(29.2)$ & 0.002 \\
\hline
\end{tabular}

Values are $\mathrm{n}(\%)$ unless otherwise specified. CR: complete remission; PR: partial remission; CKD: chronic kidney disease; eGFR: estimated glomerular filtration rate; IQR: interquartile range.

$\mathrm{ml} / \mathrm{min} / 1.73 \mathrm{~m}^{2}, 180.0 \pm 161.7 \mathrm{IU} / \mathrm{ml}, 36.3 \pm 18.9 \mathrm{mg} / \mathrm{dl}, 24.0$ \pm 10.6 , respectively (compared with $401.5 \pm 191.4 \mu \mathrm{mol} / \mathrm{l}$, $16.0 \pm 10.6 \mathrm{ml} / \mathrm{min} / 1.73 \mathrm{~m}^{2}, 114.5 \pm 116.5 \mathrm{IU} / \mathrm{ml}, 35.0 \pm 21.4$ $\mathrm{mg} / \mathrm{dl}, 20.9 \pm 8.3$, respectively, in patients not treated with plasmapheresis; $\mathrm{p}=0.835,0.431,0.478,0.909$, and 0.52 , respectively). Among the 4 patients treated with plasmapheresis, one reached $\mathrm{CR}$ at 12 months, and there was no apparent effect of plasmapheresis on renal or patient survival.

LN patients with renal TMA showed inferior renal survival rate and a higher occurrence rate of stage 3 or above CKD at last followup (70\% at $5 \mathrm{yrs}$, and $66.6 \%$, respectively, compared with $95 \%$, and $29.2 \%$ in non-TMA controls; $\mathrm{p}=0.023$ and 0.002 , respectively; Figure 2A). The TMA group also showed lower median eGFR value at last followup compared with non-TMA controls $(50.1 \mathrm{ml} / \mathrm{min}$, IQR 7-132 $\mathrm{ml} / \mathrm{min}$, vs $85.0 \mathrm{ml} / \mathrm{min}$, IQR $12-147 \mathrm{ml} / \mathrm{min} ; \mathrm{p}=0.003$; Table 3). Univariate analyses showed that renal TMA (HR 9.702, 95\% CI 1.596-58.96; $\mathrm{p}=0.014)$ and histological activity (HR 1.183, 95\% CI 1.004-1.394; $\mathrm{p}=0.044$ ) were risk factors for renal failure but not chronicity and SLEDAI score at presentation (HR 1.245 and 1.046, 95\% CI $0.917-1.690$ and $0.981-1.116$, respectively; $\mathrm{p}=0.161$ and 0.169 , respectively). Multivariate analyses further demonstrated that only renal TMA was an independent risk factor for renal failure (HR 7.164, 95\% CI 1.077-47.64; $\mathrm{p}=0.042$ ) after adjusting for histological activity and chronicity, and SLEDAI scores at presentation. Anti-dsDNA titer at presentation and serum creatinine at 1 year showed inverse relationships with renal survival during followup in the TMA group $(\mathrm{r}=-0.628$ and -0.540 , respectively; $\mathrm{p}=0.001$ and 0.006$)$, but not in non-TMA patients ( $\mathrm{r}=-0.121$ and -0.265 respectively; $\mathrm{p}=0.541$ and 0.086 ). Renal survival during followup was not associated with age, sex, induction, or maintenance immunosuppressive regimen, serum creatinine, proteinuria, C3 level, anti-Ro seropositivity, activity index, chronicity

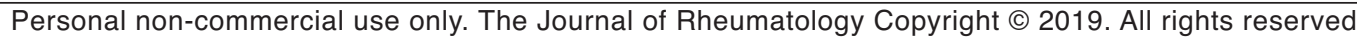



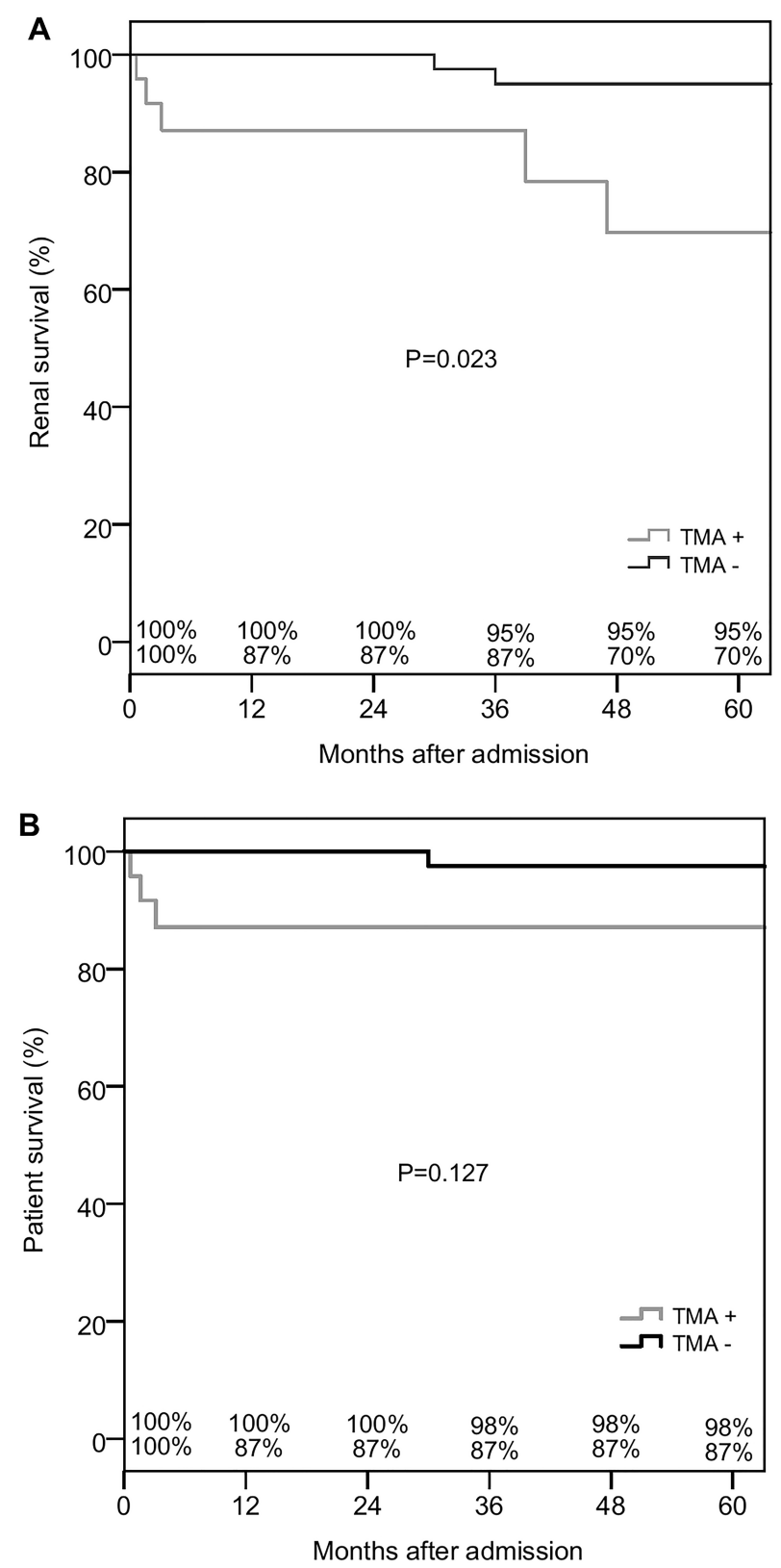

Figure 2. (A) Renal and (B) patient survival rates of lupus nephritis patients with or without renal thrombotic microangiopathy (TMA).

index, hemoglobin level, leukocyte and platelet counts, and SLEDAI at presentation ( $p>0.05$ for all). Three patients with renal TMA died during followup: 2 of pneumonia and 1 from serial complications following thrombocytopenia-associated bleeding after renal biopsy. Two patients without renal TMA died, one because of myocardial infarction and the other from dialysis-related peritonitis. Patient survival rate after 5 years was similar between renal TMA and non-TMA patients (87\% and $98 \%$, respectively; $\mathrm{p}=0.127$; Figure $2 \mathrm{~B}$ ).

\section{DISCUSSION}

Renal TMA is associated with unfavorable short- and longterm renal outcomes in patients presented with classical and atypical HUS, TTP, and hypertensive crisis ${ }^{6}$. LN is an important cause of acute kidney injury and CKD in Asia ${ }^{1,11}$, but there are few data on the prevalence of renal TMA and its effect on clinical outcomes. Renal TMA features have been reported in $0.5-9 \%$ of Japanese and white patients with $\mathrm{LN}$, and up to $24 \%$ in a report from China ${ }^{9,21,22,23,24}$. In our retrospective study we included a big sample size of 677 patients with biopsy-proven LN, and the results show that renal TMA is relatively uncommon, occurring at a prevalence of about $3.5 \%$. Though uncommon, the data show that the detection of renal TMA is of clinical significance, because it is associated with more severe disease and histological evidence of kidney injury at presentation, and also portends a less favorable longterm renal prognosis. A retrospective study from China had reported more aggressive renal presentation in LN patients with $\mathrm{TMA}^{9}$, but had included patients with antiphospholipid syndrome, malignant HTN, and SSc with heterogeneous management, and thus the effect of renal TMA on longterm outcomes in LN patients could not be discerned. In our present study we included LN patients (with the renal TMA features confirmed by a third-party pathologist) and non-TMA LN patients matched for important clinical and treatment characteristics as controls in the analysis of longterm clinical outcomes. Our finding of a higher requirement for acute hemodialysis at presentation was not reported in other series. The higher rate of anti-Ro seropositivity (45\%) in the TMA group in our series, compared with non-TMA controls (18\%) and also the data from an earlier report, is intriguing ${ }^{25}$. Further studies are required for reconfirmation and to investigate whether this is of pathogenic significance. In this context, a study in Mexico reported that $39 \%$ of LN patients with TMA were seropositive for anti-Ro ${ }^{8}$. Associations between anti-Ro antibodies and cutaneous vasculitis, TTP, renal involvement, and pulmonary HTN in SLE have been reported $25,26,27$. The relationship between anti-Ro antibodies and TMA, however, remains poorly understood, and the putative effects of anti-Ro on endothelial cells (e.g., accelerated endothelial cell apoptosis with increased vascular intimal thickness) might have contributed to the increased risk of TMA ${ }^{28,29,30}$.

Our current data demonstrated that $\mathrm{LN}$ patients with renal TMA showed inferior longterm renal prognosis compared with non-TMA patients despite the similar initial short-term response rates. The data suggest that this is likely related to the more severe chronic renal damage already present at baseline in TMA patients, since the 2 groups did not differ in their subsequent renal flare rates (data not shown), as we and others have highlighted the adverse effect of renal flares on longterm renal survival ${ }^{31,32,33,34,35}$. In our current study, LN patients with renal TMA had a renal survival rate of $70 \%$ after 5 years, which may appear non-inferior or more favorable than the results from other investigators ${ }^{6,7,8}$, but is clearly inferior to the renal prognosis that we reported previously ${ }^{1}$.

Personal non-commercial use only. The Journal of Rheumatology Copyright @ 2019 . All rights reserved. 
The association between longterm renal outcome and serum creatinine at 1 month not only underscores the importance of early diagnosis and prompt initiation of effective induction treatment, but also provides a useful prognostic tool that could prompt thorough reassessment of the adequacy of response, including a repeat kidney biopsy, if deemed necessary. The limited experience with plasmapheresis, given in highly selected patients, does not allow drawing conclusions on its effect. The limitations of this study include its retrospective features and the different healthcare settings of the 2 centers. Notwithstanding, our data were derived from a big series of 677 biopsy-proven LN cases and the histological features were independently reevaluated by a third-party pathologist, and thus should represent a fairly accurate real-world experience of this uncommon condition, providing clinically important information to clinicians.

Renal TMA is an uncommon finding in $\mathrm{LN}$ but is associated with more severe clinical and histopathological renal disease, and inferior longterm renal outcomes.

\section{REFERENCES}

1. Yap DY, Tang CS, Ma MK, Lam MF, Chan TM. Survival analysis and causes of mortality in patients with lupus nephritis. Nephrol Dial Transplant 2012;27:3248-54.

2. Saxena R, Mahajan T, Mohan C. Lupus nephritis: current update. Arthritis Res Ther 2011;13:240.

3. Weening JJ, D'Agati VD, Schwartz MM, Seshan SV, Alpers CE, Appel GB, et al. The classification of glomerulonephritis in systemic lupus erythematosus revisited. J Am Soc Nephrol 2004;15:241-50.

4. Wu LH, Yu F, Tan Y, Qu Z, Chen MH, Wang SX, et al. Inclusion of renal vascular lesions in the 2003 ISN/RPS system for classifying lupus nephritis improves renal outcome predictions. Kidney Int 2013;83:715-23.

5. Hughson MD, Nadasdy T, McCarty GA, Sholer C, Min KW, Silva F. Renal thrombotic microangiopathy in patients with systemic lupus erythematosus and the antiphospholipid syndrome. Am J Kidney Dis 1992;20:150-8.

6. Barbour T, Johnson S, Cohney S, Hughes P. Thrombotic microangiopathy and associated renal disorders. Nephrol Dial Transplant 2012;27:2673-85

7. Yu XJ, Yu F, Song D, Wang SX, Song Y, Liu G, et al. Clinical and renal biopsy findings predicting outcome in renal thrombotic microangiopathy: a large cohort study from a single institute in China. ScientificWorldJournal 2014;2014:680502.

8. Barrera-Vargas A, Rosado-Canto R, Merayo-Chalico J, Arreola-Guerra JM, Mejia-Vilet JM, Correa-Rotter R, et al. Renal thrombotic microangiopathy in proliferative lupus nephritis: risk factors and clinical outcomes: a case-control study. J Clin Rheumatol 2016;22:235-40.

9. Song D, Wu LH, Wang FM, Yang XW, Zhu D, Chen M, et al. The spectrum of renal thrombotic microangiopathy in lupus nephritis. Arthritis Res Ther 2013;15:R12.

10. Isenberg D, Appel GB, Contreras G, Dooley MA, Ginzler EM, Jayne D, et al. Influence of race/ethnicity on response to lupus nephritis treatment: the ALMS study. Rheumatology 2010; 49:128-40.

11. Jakes RW, Bae SC, Louthrenoo W, Mok CC, Navarra SV, Kwon N. Systematic review of the epidemiology of systemic lupus erythematosus in the Asia-Pacific region: prevalence, incidence, clinical features, and mortality. Arthritis Care Res 2012;64:159-68.
12. Adler M, Chambers S, Edwards C, Neild G, Isenberg D. An assessment of renal failure in an SLE cohort with special reference to ethnicity, over a 25-year period. Rheumatology 2006;45:1144-7.

13. Chan TM, Li FK, Tang CS, Wong RW, Fang GX, Ji YL, et al. Efficacy of mycophenolate mofetil in patients with diffuse proliferative lupus nephritis. Hong Kong-Guangzhou Nephrology Study Group. N Engl J Med 2000;343:1156-62.

14. Yap DY, Ma MK, Mok MM, Tang CS, Chan TM. Long-term data on corticosteroids and mycophenolate mofetil treatment in lupus nephritis. Rheumatology 2013;52:480-6.

15. Koo HS, Kim YC, Lee SW, Kim DK, Oh KH, Joo KW, et al. The effects of cyclophosphamide and mycophenolate on end-stage renal disease and death of lupus nephritis. Lupus 2011;20:1442-9.

16. Rathi M, Goyal A, Jaryal A, Sharma A, Gupta PK, Ramachandran $\mathrm{R}$, et al. Comparison of low-dose intravenous cyclophosphamide with oral mycophenolate mofetil in the treatment of lupus nephritis. Kidney Int 2016;89:235-42.

17. Lee PY, Yeh KW, Yao TC, Lee WI, Lin YJ, Huang JL. The outcome of patients with renal involvement in pediatric-onset systemic lupus erythematosus - a 20-year experience in Asia. Lupus 2013; 22:1534-40

18. Kono M, Yasuda S, Kato M, Kanetsuka Y, Kurita T, Fujieda Y, et al Long-term outcome in Japanese patients with lupus nephritis. Lupus 2014;23:1124-32

19. Chen MH, Chen MH, Chen WS, Mu-Hsin Chang P, Lee HT, Lin HY, et al. Thrombotic microangiopathy in systemic lupus erythematosus: a cohort study in North Taiwan. Rheumatology 2011;50:768-75.

20. Hochberg MC. Updating the American College of Rheumatology revised criteria for the classification of systemic lupus erythematosus. Arthritis Rheum 1997;40:1725.

21. Banfi G, Bertani T, Boeri V, Faraggiana T, Mazzucco G, Monga G, et al. Renal vascular lesions as a marker of poor prognosis in patients with lupus nephritis. Gruppo Italiano per lo Studio della Nefrite Lupica (GISNEL). Am J Kidney Dis 1991;18:240-8.

22. Barber C, Herzenberg A, Aghdassi E, Su J, Lou W, Qian G, et al. Evaluation of clinical outcomes and renal vascular pathology among patients with lupus. Clin J Am Soc Nephrol 2012;7:757-64.

23. Tsumagari T, Fukumoto S, Kinjo M, Tanaka K. Incidence and significance of intrarenal vasculopathies in patients with systemic lupus erythematosus. Hum Pathol 1985;16:43-9.

24. Descombes E, Droz D, Drouet L, Grunfeld JP, Lesavre P. Renal vascular lesions in lupus nephritis. Medicine 1997;76:355-68.

25. Li J, Leng X, Li Z, Ye Z, Li C, Li X, et al. Chinese SLE treatment and research group registry: III. association of autoantibodies with clinical manifestations in Chinese patients with systemic lupus erythematosus. J Immunol Res 2014;2014:809389.

26. Fukuda MV, Lo SC, de Almeida CS, Shinjo SK. Anti-Ro antibody and cutaneous vasculitis in systemic lupus erythematosus. Clin Rheumatol 2009;28:301-4.

27. Merayo-Chalico J, Demichelis-Gomez R, Rajme-Lopez S, Aparicio-Vera L, Barrera-Vargas A, Alcocer-Varela J, et al. Risk factors and clinical profile of thrombotic thrombocytopenic purpura in systemic lupus erythematosus patients. Is this a distinctive clinical entity in the thrombotic microangiopathy spectrum?: a case control study. Thromb Res 2014;134:1020-7.

28. Vaudo G, Bocci EB, Shoenfeld Y, Schillaci G, Wu R, Del Papa N, et al. Precocious intima-media thickening in patients with primary Sjogren's syndrome. Arthritis Rheum 2005;52:3890-7.

29. Silva LM, Garcia AB, Donadi EA. Increased lymphocyte death by neglect-apoptosis is associated with lymphopenia and autoantibodies in lupus patients presenting with neuropsychiatric manifestations. J Neurol 2002;249:1048-54.

30. Stoneman VE, Bennett MR. Role of apoptosis in atherosclerosis and its therapeutic implications. Clin Sci 2004;107:343-54. 
31. Parikh SV, Nagaraja HN, Hebert L, Rovin BH. Renal flare as a predictor of incident and progressive CKD in patients with lupus nephritis. Clin J Am Soc Nephrol 2014;9:279-84.

32. Illei GG, Takada K, Parkin D, Austin HA, Crane M, Yarboro CH, et al. Renal flares are common in patients with severe proliferative lupus nephritis treated with pulse immunosuppressive therapy: long-term followup of a cohort of 145 patients participating in randomized controlled studies. Arthritis Rheum 2002;46:995-1002.

33. Gibson KL, Gipson DS, Massengill SA, Dooley MA, Primack WA, Ferris MA, et al. Predictors of relapse and end stage kidney disease in proliferative lupus nephritis: focus on children, adolescents, and young adults. Clin J Am Soc Nephrol 2009;4:1962-7.

34. Mejia-Vilet JM, Cordova-Sanchez BM, Arreola-Guerra JM, Morales-Buenrostro LE, Uribe-Uribe NO, Correa-Rotter R. Renal flare prediction and prognosis in lupus nephritis Hispanic patients. Lupus 2016;25:315-24.

35. Yap DY, Tang C, Ma MK, Mok MM, Chan GC, Kwan LP, et al. Longterm data on disease flares in patients with proliferative lupus nephritis in recent years. J Rheumatol 2017;44:1375-83. 